\title{
FLIPPED CLASSROOM IN LANGUAGE STUDIES: A CONTENT ANALYSIS OF RECENT ARTICLES
}

\author{
Hana Dler Ahmed ${ }^{1}$, Gulsum Asiksoy 2,* \\ ${ }^{1}$ Department of Computer Education and Educational Technology, Ataturk Education Faculty, Near East \\ University, North Cyprus, Via Mersin 10, Turkey, hana.majeed90@yahoo.com \\ ${ }^{2}$ Department of Computer Education and Educational Technology, Ataturk Education Faculty, Near East \\ University, North Cyprus, Via Mersin 10, Turkey, gulsum.asiksoy@ neu.edu.tr \\ Correspondence: gulsum.asiksoy@ neu.edu.tr ; Tel.: +90 (392) 2236464
}

\begin{abstract}
The concept of the flipped or inverted classroom has become a growing technological advancement in the field of instructional education. It is a growing instructional approach, also known as a pedagogical approach in which the standard, or the conventional pattern of classroom is altered. The traditional and commonly known approach is reversed by providing the instructional contents to the students outside the boundaries of the classroom. The actual classroom is replaced by videos of course contents to be watched at home by students while the students converge in the classroom for activities that help ingrain the learnt concepts. Lately, quite a lot of studies have been conducted on the flipped classroom in different subjects of study. In this research, we will evaluate the significance of the flipped classroom based on its application to language studies and learning. A total of 20 papers were carefully selected from this field and thoroughly examined for the purpose of the research. It was concluded that the flipped classroom has gained major significance in several fields of study including hands-on fields like medicine, nursing and engineering. This research is a comprehensive pilot to instructors and researchers alike in the quickly growing field of flipped classroom.
\end{abstract}

Keywords: flipped classroom, inverted classroom technology, education, content-analysis

\section{Introduction}

Quite a lot of internet dependent technologies have been introduced to our day-to-day lives, with them gaining improved level of acceptance over time (Sams, 2012). Many of such technologies have introduced interactions and multimedia features that improve learning (Avci, Vasu, Oliver, Keene \& Fusarelli, 2014). Due to the pivotal positioning of language in learning, educational and instructional technologies have also gained application in the presentation of language course contents to students by the instructor (Hsieh, Wu \& Marek, 2017). This gives the students a privilege to study the learning materials ahead of the classroom session while the usual classroom session is majorly used to elaborate on the ideas learnt previously and obtain a deeper understanding of associated contents by the use of group discussion or inquiries and tackling of problems as guided by the instructor. It indirectly moves the homework and other activities into the classroom while the lecture session is made into video contents for the students to watch online at home, contrary to the structure of traditional learning environment (Asiksoy \& Ozdamli, 2016). Computer based approaches would be applied to perform lexical analysis of the reviewed papers with the introduction of minor statistical approaches, through which we will obtain clear and reliable information, thus making feasible recommendations through the use of content analysis. 
The following are the design principles required for the flipped classroom:

- Introducing students to the primary knowledge ahead of class activities,

- Motivates students in preparation for the class activities by watching online lectures,

- Structuring the evaluation methods,

- Bringing a connection between activities performed within the classroom and those performed outside the classroom,

- Provision of appropriate guidance to the students,

- Helps students to form a community of learners,

- Provides quick reaction or feedback about practice work,

The benefits of flipped classroom approach appear to be many, as it provides 'beyond the classroom' form of learning where students learn in the comfort of their homes at acceptable paces. Also, while engaged in discussions and reviews with the instructor, they enjoy the privilege of having a personal time with the instructors (Mate \& Salinas, 2014; Roach, 2014).

Consequently, the paper is organized as follows. We examine previous work done by researchers in the fields of flipped learning, language study and content analysis approach. Following this, we propose a theory in the methodology in order to fill the gap of research in content analysis and flipped learning when applied to language learning. We conclude with the impacts, the recommendations and the research conclusion. Some existing studies conducted on the application of flipped classroom on language study in education have been examined. A review of them are summarized here.

Chen Hsieh, Wu and Marek (2017), employed Wen's Output-driven/Input-enabled model in order to setup a complete oral teaching course in having an online section for written and verbal communication. For which the LINE application was used on mobile devices. It was gathered from the results that the theory dependent flipped mode of instruction had a positive effect on the motivation of the 'students', improved their use of idiomatic expressions in the classroom, as well as their general idiomatic knowledge. Also, Hung (2015), made an attempt at flipping the English language classroom in order to improve active learning. The study sought to identify the effects of flipping the classroom such as performance differences, disposition to learning and the level of participation by the students using three approaches to flipped classroom. The results showed that the flipped classroom approach had more effectiveness on the learning of the participants. Evaluating participation, the authors had 2 flip categories (flip and semi-flip) with 26 and 24 participants respectively. The mean of their participation was recorded as well as the standard deviation and evaluated with t-tests as seen on Table 1.

Table 1. Descriptive Statistics and İndependent Samples T-Test Results for Comparing Students' Study Time and Effort in the Structured Versus Semi-Structured Flipped Classrooms

\begin{tabular}{lllllll}
\hline & Group & $\mathbf{N}$ & Mean & $\boldsymbol{S D}$ & $\boldsymbol{t}$ & $\boldsymbol{P}$ \\
\hline Study time in minutes & Flip & 26 & 68.08 & 24.98 & 2.78 & $.008^{*}$ \\
\hline & Semi-flip & 24 & 53.33 & 19.71 & & \\
\hline Number of attempts for videos & Flip & 26 & 2.31 & 0.68 & 2.30 & $0.26^{*}$ \\
\hline & Semi-flip & 24 & 1.75 & 0.74 & & \\
\hline
\end{tabular}

Note: significance $* \mathrm{p}<.05$ 
It could be deduced from Table 1 that increased participation level was enjoyed by students of the flipped above those of students in the semi flipped classroom with a confidence level of .05 . Thus promoting the rationale that, more than the flip, the structure of the flipped classroom also plays a significant role in the participation level of the participants, suggesting the evident advantages of the application of the flipped teaching approach to language learning.

\subsection{Flipped Learning}

Considering the instances found in various research works, it is certain that the flipped classroom model has gained wide application in various fields.

In (Rotellar \& Cain, 2016), the authors recognized reasons why flipped learning is a more effective approach to learning, flipped classroom reduces academic imbalances, makes students more accountable for their performances while increasing their learning. They presented evidence of the improved academic performance caused by flipped learning in a pharmacy education class in which students' grades upped from 21 students with A, 66 students with $\mathrm{B}, 12$ students with $\mathrm{C}$ and 1 student with $\mathrm{F}$ (obtained during traditional teaching approach) to 52 students with A, 44 students with B, 4 students with C, and no student with F. Also, they present unanswered questions requiring further study in flipped classroom; for courses where the introduction of flipped classroom affects the entire curriculum, a pressing question could be "how to establish if novel characteristics exist that can forecast the success of the participating students?" another question proposed by the authors is "will graduates of a flipped classroom possess the understanding of basic facts of the flipped course?". Thirdly, the authors proposed the question "the possibility of implementing strategies and techniques that are more effective and productive within flipped classroom”.

As recognized, the following are the four pillars of the F.L.I.P.TM model (García-Peñalvo, Fidalgo-Blanco, Sein-Echaluce \& Conde, 2017);

- Flexible environment,

- Learning culture,

- Intentional content,

- Professional educator.

\subsection{Content Analysis}

This is a research approach where written, spoken or visual data is described either by numerical descriptors (quantitative) or text based descriptors (qualitative). Due to its versatility, it can be applied to recent materials gathered by researchers and academicians in an attempt to categorize open-ended responses obtained from interviewees. It can be applied to; questionnaires, print media, visual media etc. Of all its advantages, the most notable is that it can be applied to social occurrences non-invasively. The following are pivotal questions that must be considered in every content analysis (Krippendorff, 2004);

- Which data is to be analyzed?

- How are they defined?

- From what population are they drawn?

- What is the relevant context?

- What are the limits of the analysis?

- What is being measured?

In the basic form, content analysis evaluates distinct characteristics (such as word frequency) of the text contained in the document. This approach has limited analytical effectiveness as meaning of words is largely dependent on neighboring words in the context. 


\section{Methodology}

In this paper, we have performed content analysis on 20 selected publications detailing on flipped classroom in the language teaching setting. For this, we have selected only recent publications ranging from year 2015 till date 2018. Certain criteria for this research work were inherited from state of the art approaches and generally accepted parameters within the field, such criteria as spelt out in previous works are;

1. What are the years of publication by papers?

2. What is the number of articles by country of publication?

3. What instructional models were used in the flipped study?

4. What areas of flipped classroom studies was researched?

5. What technology, tools or online platform have been used for implementing the flipped classroom?

6. What are the impacts of implementing the flipped classroom on the learning of the students?

7. What are the challenges of applying the flipped classroom approach?

\subsection{Number of Articles by Year of Publication}

A total of 20 articles were selected for the purpose of this research. As seen in Table 2, 6 were carefully selected from year 2015, 9 were selected from the year 2016, 3 were selected from year 2017 and the remaining 2 are the most recent journals. Selected from among year 2018 publications.

Table 2. The Distribution of the Number of articles by years

\begin{tabular}{lc}
\hline Years & Frequency $(\mathbf{f})$ \\
\hline 2015 & 6 \\
\hline 2016 & 9 \\
\hline 2017 & 3 \\
\hline 2018 & 2 \\
\hline
\end{tabular}

\subsection{Number of Articles by Country of Publication}

The articles selected were implemented in multiple countries in order to investigate the effects of the flipped classroom on a regional basis, with 1 paper having a broad scope of implementation in 3 countries (USA, China and Macau). Taiwan had the highest contribution of 5 papers between years 2015 and 2018. Table 3 contains a complete distribution of the resources by the Country in which the implementation was conducted. 
Table 3. Distribution of the Articles by the Country

$\begin{array}{ll}\text { Country } & \text { Frequency (f) }\end{array}$

\begin{tabular}{ll}
\hline Taiwan & 5 \\
\hline USA & 2 \\
\hline Korea & 1 \\
\hline Turkey & 1 \\
\hline Japan & 1 \\
\hline Russia & 1 \\
\hline Saudi Arabia & 2 \\
\hline Singapore & 1 \\
\hline Spain & 1 \\
\hline China & 2 \\
\hline Egypt & 1 \\
\hline Indonesia & 1 \\
\hline Macau & 2 \\
\hline South Korea & 1 \\
\hline
\end{tabular}

\subsection{Instructional Model Used in the Flip Study}

These are the set of guidelines on which instructors base their teaching approaches. In the reviewed papers, various models were employed distinctly while some made use of a combination of models. The following models were employed;
a. Concept attainment model
b. Integrative model
c. Lecturer discussion model
d. Direct instruction model
e. Problem based

\subsection{Areas of Flipped Study That was Researched}

The following are the areas that were researched in the selected papers.

Table 4. Area of Flipped Study That was Researched

\section{Area}

Frequency (n)

\begin{tabular}{ll}
\hline University Level English & 6 \\
\hline English as Foreign Language & 3 \\
\hline English for Vocational Education & 1 \\
\hline Secondary School & 3 \\
\hline English for Specific Purposes & 2 \\
\hline English for Academic Purposes & 1 \\
\hline
\end{tabular}




\subsection{Technology, Tools or Online Platform Used in the Implementation}

Various tools were used in the selected papers for the purpose of the research as required by the authors.

Table 5. Frequency of Usage of Technology in Papers

Technology/Tool/Online Platform

Frequency (n)

\begin{tabular}{ll}
\hline Television sitcom & 1 \\
\hline LINE mobile app & 1 \\
\hline Shared Video & 8 \\
\hline Edmondo website & 1 \\
\hline YouTube & 3 \\
\hline Screenomatic & 1 \\
\hline Padlet & 1 \\
\hline Moodle & 1 \\
\hline WebQuest & 1 \\
\hline TED-Ed & 1 \\
\hline Screencast & 1 \\
\hline Keynote & 1 \\
\hline Doctopus & 1 \\
\hline
\end{tabular}

\subsection{Impacts of Flipped Classroom on Students Learning}

After the review of the selected papers, the following impacts of the flipped classroom in language teaching were gathered;

Table 6. Showing the Impact of Flipped Classroom on Participants

\begin{tabular}{ll}
\hline Impact & Frequency (f) \\
\hline Enhanced student engagement & 3 \\
\hline Increased student performance & 5 \\
\hline Strengthened course design & 1 \\
\hline Improved learning attitudes & 3 \\
\hline Enhanced participants' motivation & 3 \\
\hline Improved participants' knowledge & 1 \\
\hline Improved learner autonomy & 1 \\
\hline Increased students' interaction & 1 \\
\hline
\end{tabular}




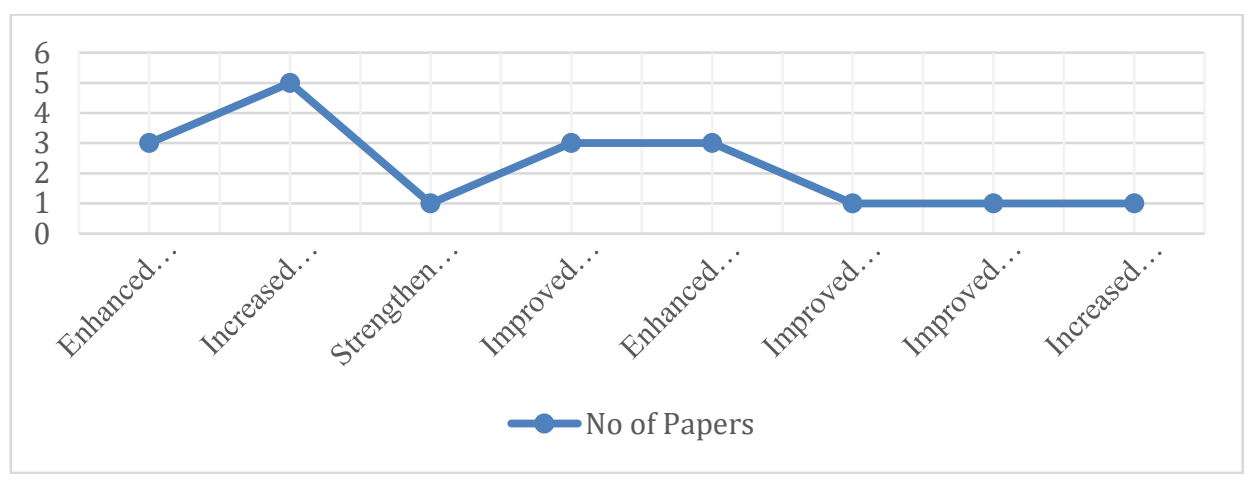

Figure 1. Showing the Impact of Flipped Learning on Students

\subsection{Challenges of Applying the Flipped Classroom Approach}

Regardless of the obvious benefits of the flipped classroom approach, some certain challenges are inherent. As identified during the study, they are listed in the following table.

Table 7. Showing the Various Challenges in the Implementation of Flipped Classroom as Specified in the Papers

\section{Challenges}

Frequency (f)

\begin{tabular}{ll}
\hline Approach best reserved for teaching and learning procedural knowledge & 3 \\
\hline Student may receive insufficient input, output due to time constraint & 1 \\
\hline Students may prefer the traditional approach & 3 \\
\hline Preparation and perception of students & 1 \\
\hline Lack of internet access & 3 \\
\hline Students may not watch videos & 3 \\
\hline Passive approach & 2 \\
\hline Challenge of producing material & 3 \\
\hline
\end{tabular}

\section{Discussion and Conclusion}

Due to the fact that changes now exist in the teaching landscape with the integration of technology, changes also are expected in the effectiveness of educationists and academicians. Such powerful change has been investigated in this paper. From the paper, it was gathered that most of the implementations of the flipped classroom was done in Taiwan, while the most significant impact of flipped classroom was 'improvement in performance' with an impact ratio of $27.7 \%$ among 8 noted impacts. Also, some of the major challenges experienced by the researchers in the study are the possibility of students to be lazy and not watch scheduled videos at home, possible lack of required technological infrastructure, possibility of some courses not being conformable to the flipped approach and the actual fact that some students may absolutely dislike the flip idea.

\section{References}

Al-Harbi, S. S., \& Alshumaimeri, Y. A. (2016). The flipped classroom impact in grammar class on EFL Saudi secondary school students' performances and attitudes. English Language Teaching, 9(10), 60-80. 
Alsowat, H. (2016). An EFL flipped classroom teaching model: Effects on English language higher-order thinking skills, student engagement and satisfaction. Journal of Education and Practice, 7(9), 108-121.

Asıksoy, G., \& Ozdamlı, F. (2016). Flipped Classroom adapted to the ARCS Model of Motivation and applied to a Physics Course. Eurasia Journal of Mathematics, Science and Technology Education, 12(6), 1589-1603. doi: http://10.12973/eurasia.2016.1251

Avci, Z. Y., Vasu, E. S., Oliver, K., Keene, K. A., \& Fusarelli, B. (2014). Utilization of online technologies in mathematical problem solving at high school level: Student and teacher perceptions. World Journal on Educational Technology, 6(2), 203-217

Basal, A. (2015). The implementation of a flipped classroom in foreign language teaching. Turkish Online Journal of Distance Education, 16(4), 28-37

Chen Hsieh, J. S., Wu, W.-C. V., \& Marek, M. W. (2017). Using the flipped classroom to enhance EFL learning. Computer Assisted Language Learning, 30(1-2), 1-21. doi: http://10.1080/09588221.2015.1111910

Chilingaryan, K., \& Zvereva, E. (2016). Methodology of flipped classroom as a learning technology in foreign language teaching. Procedia-Social and Behavioral Sciences, 237(21), 1500-1504.

Correa, M. (2015). Flipping the foreign language classroom and critical pedagogies: a (new) old trend. Higher Education for the Future, 2(2), 114-125.

Doman, E., \& Webb, M. (2016). The flipped experience for Chinese university students studying English as a foreign language. TESOL Journal, 8(1), 102-141.

Evseeva, A., \& Solozhenko, A. (2015). Use of Flipped Classroom Technology in Language Learning. Procedia-Social and Behavioral Sciences, 206, 205-209.

García-Peñalvo, F. J., Fidalgo-Blanco, Á., Sein-Echaluce, M. L., \& Conde, M. Á. (2017). Cooperative Micro Flip Teaching,. Learning and Collaboration Technologies. Technology in Education. 4th International Conference, LCT 2017, Canada.

Hsieh, J. S. C., Wu, W. C. V., \& Marek, M. W. (2017). Using the flipped classroom to enhance EFL learning. Computer Assisted Language Learning, 30(1-2), 1-21. htpp://doi: 10.1080/09588221.2015.1111910

Hsueh-Hua, C., Chih-Yuan, W., \& Ching-Huei, C. (2018). Which students benefit most from a flipped classroom approach to language learning? British Journal of Educational Technology, 49(1), 56-68. htpp://doi: doi:10.1111/bjet.12530

Hung, H.T. (2015). Flipping the classroom for English language learners to foster active learning. Computer Assisted Language Learning, 28(1), 81-96. doi: htpp://10.1080/09588221.2014.967701

Hung, H.-T. (2017). Design-Based Research: Redesign of an English Language Course Using a Flipped Classroom Approach. Tesol Quarterly, 51(1), 180-192

Kang, N. (2015). The comparison between regular and flipped classrooms for EFL Korean adult learners. Multimedia-Assisted Language Learning, 18(3), 41-72.

Krippendorff, K. (2004). Content Analysis: An Introduction to Its Methodology. Beverly Hills: SAGE. 
Lee, G., \& Wallace, A. (2018). Flipped learning in the English as a foreign language classroom: Outcomes and perceptions. TESOL Quarterly, 52(1), 62-84.

Leis, A., Tohei, A., \& Cooke, S. (2015). The Effects of Flipped Classrooms on English Composition Writing in an EFL Environment. International Journal of ComputerAssisted Language Learning and Teaching (IJCALLT), 5(4), 37-51.

Liu, D. (2016). The Reform and Innovation of English Course: A Coherent Whole of MOOC, Flipped Classroom and ESP. Procedia - Social and Behavioral Sciences, 232, 280-286. doi: https://doi.org/10.1016/j.sbspro.2016.10.021

Mate, K. S., \& Salinas, G. (2014). Flipping primary health care: A personal story. Healthcare, 2(4), 280-283. doi: https://doi.org/10.1016/j.hjdsi.2014.10.003

Mehring, J. (2016). Present Research on the Flipped Classroom and Potential Tools for the EFL Classroom. Computers in the Schools, 33(1), 1-10. http://doi: 10.1080/07380569.2016.1139912

Roach, T. (2014). Student perceptions toward flipped learning: New methods to increase interaction and active learning in economics. International Review of Economics Education, 17, 74-84. http://doi: https://doi.org/10.1016/j.iree.2014.08.003

Rotellar, C., \& Cain, J. (2016). Research, Perspectives, and Recommendations on Implementing the Flipped Classroom. American Journal of Pharmaceutical Education, 80(2), 1-4.

Sams, J. B. A. (2012). Flip Your Classroom: Reach Every Student in Every Class Every Day 1. ed., Washington: ISTE Publishing.

Soliman, N. A. (2016). Teaching English for Academic Purposes via the Flipped Learning Approach. Procedia - Social and Behavioral Sciences, 232, 122-129. htpp://doi: https://doi.org/10.1016/j.sbspro.2016.10.036

Webb, M., \& Doman, E. (2016). Does the Flipped Classroom Lead to Increased Gains on Learning Outcomes in ESL/EFL Contexts? CATESOL Journal, 28(1), 39-67.

\section{Biodata of the Corresponding Author}

Asst. Prof. Dr. Gülsüm Aş1ksoy has completed her B.Sc degree in Physics Engineering at Ankara University. Between 1995 and 2006 she worked in private sector in the various field (computer, electronic security) as a planning engineer in Ankara, Turkey. She received her M.Sc degree in Electrical and Electronic Engineering in 2011. She received her $\mathrm{PhD}$ in Computer Education and Instructional Technology. She teaches general physics, game-based learning, gamification in education, distance education, research methods and technics courses as undergraduate and master level courses. Her research interests include flipped learning, gamification in learning and instruction, interactive simulations for teaching and learning physics, digital games and simulations and artificial neural networks. She is currently vice chair of Department of Mathematics and Science Education. 